\title{
A Study on the Prevalence of Dengue Virus Infection using NS1 Antigen and IgM Antibody capture ELISA for the Early Diagnosis in and around Madurantakam, India
}

\author{
R. Ganesan, T. Sheila Doris Devamani, D. Joseph Pushpa Innocent ${ }^{*}$
}

Department of Microbiology, Karpaga Vinayaga Institute of Medical Sciences and Research Centre, Chinnakolambakkam, Madurantakam Taluk, Kanchipuram District, Tamilnadu, India

*Corresponding author

\section{A B S T R A C T}

Dengue is a mosquito borne viral disease (Priyadarshini et al., 2016). It belongs to the family of Flavivirus. It is transmitted mainly by the bite of Aedes aegypti mosquito. Outbreaks are due to the four serotypes DEN1, DEN2, DEN3, DEN4. Increasing incidence

\section{Keywords}

Dengue fever, NS1-

Antigen, IgM

antibody, Rapid

diagnosis, ELISA

Article Info

\section{Accepted:}

12 January 2019

Available Online:

10 February 2019 and repeated outbreaks turns this disease as a serious public health problem (Barrera et al., 2002). Urbanization, improper water management and the vector population are the main causes for the spread of the disease. Dengue is a leading causes of hospitalization and death among children (Mistry et al., 2013). Objective of the study is to determine the prevalence of dengue cases in this rural area at present. This descriptive study was conducted in our hospital for a period of one year between April 2017 and March 2018. A total of 245 Serum samples were collected from clinically suspected dengue patients attended the out patient department of Karpaga Vinayaga Institute of Medical Science and Research Centre, Sera were tested by capture ELISA for the presence of dengue NSlantigen and IgM antibodies. The data were analyzed. Out of 245 samples 111 were showed positive for dengue virus infection. The positive peak values were observed between the months August and December. The maximum positivity was observed in the age group between 16-45 years. Male and female were affected equally. In conclusion, the present study results showed that the study region is endemic for dengue virus infection and there is an urgent need for the continuous monitoring to prevent further transmission of the disease to the community, for which early diagnosis is essential. It can be best done together with dengue NS1 antigen and IgM antibody detection by capture ELISA.

\section{Introduction}

Dengue is a mosquito borne viral fever. It is caused by flavivirus and it is a positive singlestranded encapsulated RNA virus. Dengue outbreaks by four serotypes DEN1, DEN2, DEN3, DEN4 (WHO, 2014). In 2013 a fifth variant DEN5 has been isolated few years back in Bangkok (Mustafa et al., 2015). However this serotype follows the sylvatic cycle. Despite genetic variations each of the dengue serotypes results in the same diseases and clinical symptoms. In India Dengue was first reported in 1946, but as per the latest reports prevalence of almost all the serotypes are found in India (Gupta et al., 2012). 
Outbreaks have been reported from different parts of the country (Parida et al., 2002). Dengue was classified as the most important mosquito-borne viral disease by World Health Organization in 2012. Infection transmitted mainly by Aedes aegypti mosquito and also by Aedes albopictus (WHO, 2012). The vector Aedes aegypti is a day biting mosquito that breeds in natural water (Abhra Banerjee et al., 2018). Dengue infection is a systemic and dynamic disease. It is an acute febrile illness causing significant morbidity and mortality (Apurba et al., 2016). Dengue causes a wide spectrum of illness from mild symptomatic illness to severe fatal dengue hemorrhagic fever/dengue shock syndrome (DHF/DSS) (Gargi Ghosh et al., 2013). Dengue becomes one of the leading causes of death in children. At least 21000 deaths occur mainly among children in every year. Sudden onset of fever, headache, chills followed by rashes and in some pain in joints indicated as the signs and symptoms of dengue infection. Thrombocytopenia and leucopenia are commonly encountered. In severe cases thrombocytopenia and increased vascular permeability can cause hemorrhagic shock. Neither a vaccine nor a specific anti viral therapy is not available (Wilder-Smith et al., 2004).

Diagnosis of dengue infection relies on Dengue Antigen NS1 \& Antibodies IgM and IgG. NS1 is a highly conserved glycoprotein that is needed for the viral replication. NS1 antigen is found from the day 1 to 9 days (Blacksell et al., 2008). Therefore detection of dengue NS1 antigen represents a new approach for the diagnosis of acute dengue infection in primary infection. IgM antibodies developed within 5 days on the onset of symptoms and persist for up to 3 months. IgG appears on the $14^{\text {th }}-21^{\text {th }}$ day of illness and persists for lifetime.

This immune response confers lifetime immunity against the infecting serotype but provides short duration of protection against the infection caused by different serotypes. Mortality rate in dengue infection is high during epidemics and this can be reduced by early diagnosis. The objective of the present study is to determine the prevalence of dengue among the clinically reported cases. Serum samples were tested by NS1 antigen using commercially available ELISA kits and IgM antibody were also tested by capture ELISA for the early diagnosis. This descriptive study was conducted at KIMS \& RC. This hospital caters to the rural population belonging to villages in and around Madurantakam.

\section{Materials and Methods}

A total of 245 blood samples were collected from patients, clinically suspected dengue fever with acute febrile illness, body pain, headache, myalgia, arthralgia and or bleeding tendencies for 5 or more days. Both inpatients and out patients belonging to all age groups were included in this study. The period of study was one year from April 1, 2017 to March 31,2018. Ethical clearance was obtained from the institutional ethical committee for this descriptive study.

Three $\mathrm{ml}$ of blood samples were collected aseptically and allowed at room temperature for 20 minutes to clot after retracting the clot, samples were centrifuged at 2500 RPM for 20 minutes. The clear sera on the top were collected. Samples were tested for Dengue NS1Ag MICROLISA and Dengue IgM MICROLISA by using commercially available kits and the data were analyzed.

\section{Results and Discussion}

Out of 245 samples tested, 111 (45\%) samples were positive for dengue virus infection by NS1Ag plus IgM Antibody. Among 111 positive cases, NS1 Ag alone positive in 57 (51.4\%) patients. Remaining 54 
(48.6\%) patients were positive for $\operatorname{IgM}$ Antibody (Showed in table 1). Among the 111 positive cases, 19 (17\%) samples showed positive for both NS1 Ag and IgM Antibody. Maximum positivity was observed in the age groups between 16-45 years. Both male and females were affected almost equally
(Showed in table 2). Seasonal variation was observed, on analysis only few cases were present during the month of January to July whereas the positivity peak was observed between the month of August and December (Showed in bar diagram: 1).

Table.1 NSI antigen and IgM antibody test results

\begin{tabular}{|c|l|c|c|c|}
\hline S No & Test & No of samples & No of positives & Percentage \\
\hline 1 & NS1 & 245 & 57 & $51.4 \%$ \\
\multirow{2}{*}{2} & IgM & 245 & 54 & $48.6 \%$ \\
\cline { 2 - 6 } & TOTAL NO & OF POSITIVE & 111 & \\
\hline
\end{tabular}

Table.2 Age \& group wise distribution of dengue positive cases

\begin{tabular}{|l|c|c|c|}
\hline SUBJECT & $\begin{array}{c}\text { ADULT } \\
(\mathbf{1 6 - 4 5} \text { yrs })\end{array}$ & $\begin{array}{c}\text { CHILDREN } \\
(\mathbf{0 - 1 5} \text { yrs })\end{array}$ & TOTAL \\
\hline MALE & $\mathbf{5 3}$ & $\mathbf{4}$ & $\mathbf{5 7}$ \\
\hline FEMALE & 49 & $\mathbf{5}$ & 54 \\
\hline TOTAL & 102 & 9 & 111 \\
\hline
\end{tabular}

Fig.1 Bar diagram of month wise distribution of positive cases

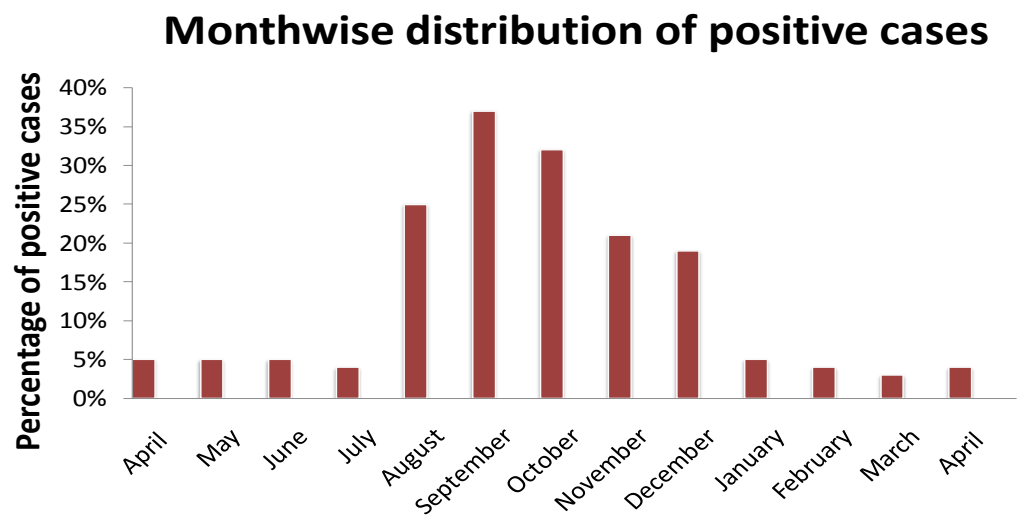

\section{Months}

The overall prevalence of dengue in the study area during the study period was $45.3 \%$ and this was higher than the study by Priyadarshini Shanmugan et al., kelambakkam. Present study also shows that the prevalence of dengue infection in male and female is almost equal and it is in contrast with the study of Priyadarshini et al., It is observed that there is a significant increase in rate of dengue infection during the month of 
August - December. This coincides with the rainy season in the state of Tamil Nadu, which favors the increased population of vectors. Yet another study in New Delhi showed that the age related positivity is high in the age group of 11-30 years further the females were affected more than males (Lall et al., 2016) 'Where as in the present study the peak level of infection is seen in the age group of 16-45 years.

A study report published by Nishat Hussain Ahmed et al., in Delhi showed a similar observation and increased prevalence in rainy season. In most of the tropical countries, dengue epidemics are reported to occur during the rainy season, due to abundant mosquito growth (Jawetz et al., 2016). It is proved in our study too. Capeding et al., (2015) reported in his study and the result revealed that the highest prevalence was seen among children in the age group between 5 and 14 years old' which is in contrast with the present study report. However the same author also explained about the seasonal trends in that positive cases showed a peak incidence during October and November which is similar to our findings. Jhansi Charles et al., in their study published, among 167 dengue positives cases, 93 were males $(55.6 \%)$ and 74 were females $(44.4 \%)$, stating that the dengue virus infection is predominant in males than in females (Jhansi et al., 2015) which is contradict to our results.

On the basis of present study results, it is concluded that NS1Ag is a useful method to diagnose dengue positivity in early stage by itself. When used in combination with IgM $\mathrm{Ab}$ test, it improves the detection rate substantially. This study shows that the dengue virus infection is prevalent in the study region and the annual prevalence rate is $45 \%$. Infection is almost equal both in male and in females. Positivity rate is higher in adult age group. Increase in the prevalence is observed during rainy and post rainy season when the vectors are present abundantly. Present study clearly shows that our region is endemic for the dengue virus infection and there is a need for the continuous monitoring to prevent the transmission of the disease and to plan effective measures, to control the spread of dengue virus infection.

\section{Acknowledgement}

Authors acknowledge gratefully to authors/ editors/ publishers of all those articles, journals and books from where the literature for this manuscript has been reviewed and discussed.

\section{References}

Abhra Banerjee, Uttam Kuar Paul, Arup Bandyopadhyay. 2018. Diagnosis of dengue fever: roles of different laboratory test methods. Int Adv Med; Apr; 5(2): 395-399.

Apurba SS, Sandhya BK. Essentials of Medical Microbiology. New Delhi. Jaypee brothers: 2016; Pp. 489-492.

Barrera R, Delgado N, Jienez M, Valero S. 2002. Eco-epidemiological factors associated with hyper endemic dengue hemorrhagic fever in Maracay city, Venezula. Dengue Bull; 26:84-95.

Blacksell, SD, Mamman, MPJr, Thangpaseuth, S., Gibbons, RV., Jarman, RG, Jenjaroen, K. 2008. Evaluation of Panbio dengue nonstructural antigen detection and immunoglobulin $\mathrm{M}$ antibody enzyme linked immunosorbent assays for the diagnosis of acute dengue infections in Laos. Diagn Microbiol Infect Dis; 60: 43-49.

Capeding, MRZ, L'Azou M, Manalaysay M, et al., 2015. Laboratory-confirmed Dengue in Children in Three Regional Hospitals in the Philippines in 
2009-2010. The Pediatric Infectious Disease Journal., 34 (11):1145-1151.

Gargi Ghosh, Urhekar AD and SusmitKosta.

2013. A Clinico microbiological study of dengue fever case in a tertiary care centre of Navi Mumbai. Int J Bioassays 2(11), 1462-1467.

Gupta N, Srivastava S, Jain A, Chaturvedi

UG. 2012. Dengue in India. Indian J

Med Res. 136: 373-90.

Jawetz, Melanick and Adelberg's Medical Microbiology, $26^{\text {th }}$ edition; Pp. 564-566.

Jhansi C, Ramesh A, Anand J, Rajendran T, Thilakavathy P, Vithiya G.. 2015. Study of Prevalence of Dengue infection in a Rurally situated Tertiary Care Medical College Hospital at Madurai, Tamilnadu. IOSR- J. Dent. Med. Sci.; 14(10): 32-36.

Lall. H, Gupta. P, Debbarma. M, Sharma. P, Ansari. S.K, Jais. M and Kaur, R. 2016 Sero-Prevalence of Dengue in Tertiary Care Hospital in Delhi. Int.J.Curr. Microbiol and App. Sci., 5(6): 439-445.

Mistry M, Goswami Y, Chudasama RK, Thakkar D. Epidemiological and demographic characteristics of dengue disease at a tertiary care centre in Saurashtra region during the year 2013. J Vector Borne Dis. 2015 Oct-Dec;
52(4): 299-303.

.Mustafa et al., 2015. A new public health dilemma in dengue control. Med $\mathbf{J}$ Armed Forces India. 71(1): 67-70.

Parida MM, Dash PK, Upadhyaya C, Saxena P, Jana AM.2002. Serological and virological investigation on an outbreak of dengue fever in Gwalior, India. Indian J Med Res; 116(2): 248-54.

Priyadarshini S, Nirupa Soundararajan, Vidya R, Preethi V. 2016 A study on the prevalence of Dengue fever in Kelambakkam in comparison to an earlier study. Indian J Microbiol Res; 3(2):102-106.

Wilder-Smith, A, Foo, W, Earnest. A, Sremulanathan. S, Paton. NI. 2004. Seroepidemiology of dengue. In the adult population of Singapore. Trop. Med. Int. Health, 9(2):305-308.

World Health organization. Dengue and severe dengue Fact sheet No 117.2014. Available at http://www.who.int/ mediacentre/factsheets/fs117/en/index.h tml\#. Accessed April 15, 2014.

World Health Organization (WHO). 2012. Global Strategy for Dengue Prevention and Control, 2012-2020. Geneva: WHO Press.

\section{How to cite this article:}

Ganesan, R., T. Sheila Doris Devamani and Joseph Pushpa Innocent, D. 2019. A Study on the Prevalence of Dengue Virus Infection using NS1 Antigen and IgM Antibody capture ELISA for the Early Diagnosis in and around Madurantakam. Int.J.Curr.Microbiol.App.Sci. 8(02): 1596-1600. doi: https://doi.org/10.20546/ijcmas.2019.802.187 